\title{
Diagnosis of rotor faults by fast Fourier transform using an auxiliary winding voltage
}

\author{
Yakout Khadouj Jelbaoui $^{1}$, Lamiaa El Menzhi' ${ }^{2}$, Abdallah Saad ${ }^{3}$ \\ ${ }^{1,2}$ National School of Applied Sciences, Abdelmalek Essaadi University, Tangier, Morocco \\ ${ }^{3}$ National Higher School of Electricity and Mechanic, Hassan 2 University, Casablanca, Morocco
}

\section{Article Info \\ Article history: \\ Received May 20, 2021 \\ Revised Sep 15, 2021 \\ Accepted Sep 30, 2021}

\section{Keywords:}

Auxiliary winding

Diagnosis

Fast Fourier transform

Modeling

Squirrel cage motor

\begin{abstract}
Condition monitoring and on-line detection have attracted several researchers in order to carry out an efficient diagnosis of machine failures. Therefore, the detection in early stage avoids system breakdown and reduce the maintenance cost. This paper presents a new diagnosic approach to detect the broken bars and broken end ring faults for a squirrel cage induction machine based on the fast Fourier transform analysis applied on a new signature as the voltage of an auxiliary winding. The auxiliary winding is a small coil inserted between two of the stator phases, the explicit expression of its voltage is presented. The signal is monitored in six faults cases under a different load level, the emergence of the fault frequencies changes for each kind of failure. The successfully simulation results obtained show the effectiveness of this approach.
\end{abstract}

This is an open access article under the $\underline{C C B Y-S A}$ license.



\section{Corresponding Author:}

Yakout Khadouj Jelbaoui

National School of Applied Sciences

Abdelmalek Essaadi University, Tangier 90000, Morocco

Email: jelbaoui.yakout@ gmail.com

\section{INTRODUCTION}

Enhancing the capabilities of monitoring and incipient fault detection becomes a must to prevent unscheduled downtimes and production process losses costs. The condition monitoring in recent years received a substantial amount attention for induction machine. The squirrel cage induction motor is an essential part in the industry sector due to its high performance and its efficiency. The variety operating environmental conditions that the motor is exposed to cause the appearance of different defects in different types of motor breakdowns [1]. The most common faults that can occur in the induction motor are 1) roller bearing faults; 2) opening or shorting stator circuiting faults; 3 ) broken rotor bars and end rings faults; 4) static or dynamic air-gap eccentricity [2], these faults can seem gradually without any symptoms with increasing stress to the adjacent bars causing progressively its deterioration and a total motor damage. Therefore, online monitoring and diagnosis approaches are of paramount importance to detect failures in early stage. This avoids engine damage and reduce production shutdowns.

Fast Fourier transform (FFT) is a powerful digital signal processing (DSP) tool that converts a signal from displaying in time domain to the frequency domain in order to generate the power spectral density, which can describe the signal by its frequency spectrum [3]-[6]. The spectrum analyser presents the magnitude information about the frequency component of the converted signal which can be easier to investigate. Choosing a proper Signal is a challenging task for monitoring by the spectral analysis technique [7]-[13].

$10 \%$ of the total motor fault are related to the rotor, but the asymmitry produced in this case can be the subject of mechanical or thermal failures, thus a significant malfunction in the motor. Besides that, 
broken rotor bars are one of the serious failures that occur in the squirrel cage induction machine. The deterioration of the bars leads to a distortion in the air-gap magnetic field and the appearance of oscillations at the speed and torque [14]. The number of the broken bars influence the oscillation amplitude and generate a mechanical vibration. More specifically, the breakage gives rise to a fault field which induces in Fourier spectrum a multiple harmonic component around the fundamental frequency [6], [15].

To improve the signal clarity of the FFT spectrum, windowing technique is used to eliminate the spectral leakage caused by discontinuities in the original signal [16]. Applying a window reduces the amplitude of the discontinuities, this technique consists of multiplying the signal in time domain by a finite length window with an amplitude that varies gradually toward zero [17]. There is different window function, the most popular are Hanning, Hamming, Blackman-Harris, Kaiser-Bessel and the flat top window. Each window has its own performances and the frequency characteristics. This frequency constitutes a spectral with a main lobe and several side lobes which affect the resulting frequency spectrum. The function window selection depends on the applications. At $95 \%$ of cases, the Hanning window has a satisfactory frequency resolution owing to its sinusoidal shape and its end side lobes which are close to zero [18].

The main novelty of this article stems from the use of the auxiliary winding voltage as a signal for the fast Fourier transform analysis using the Hanning window in order to diagnosis the broken bars and end rings failures. For that reason, the squirrel cage induction machine modeling and the proposed method description is presented to determine the monitored signal.

\section{SQUIRREL CAGE INDUCTION MACHINE MODELING}

The squirrel cage induction motor comprises a three phase windings stator and a $\mathrm{N}_{\mathrm{r}}$ bars shorted together by two identical end rings on the rotor. The rotor is represented as a mesh model constituted of multiple loops, each loops present two adjacent bars connected to portions of end rings. The study is based on the following assumptions [19], [20]:

- Sinusoidally distributed stator windings.

- Infinity iron permeability.

- Neglecting saturation.

- Uniform air gap.

- Neglecting inter-bar currents.

- Evenly distributed rotor bars.

- Neglecting flux coupling between different winding without air gap crossing.

The voltage equations for the motor can be written in vector matrix model as [21]:

$$
\begin{aligned}
& {\left[\mathrm{V}_{\mathrm{s}}\right]=\left[\mathrm{R}_{\mathrm{s}}\right]\left[\mathrm{I}_{3 \mathrm{~s}}\right]+\frac{\mathrm{d}\left[\phi_{3 \mathrm{~s}}\right]}{\mathrm{dt}}} \\
& {\left[\mathrm{V}_{\mathrm{r}}\right]=\left[\mathrm{R}_{\mathrm{r}}\right]\left[\mathrm{I}_{\mathrm{r}}\right]+\frac{\mathrm{d}\left[\phi_{\mathrm{r}}\right]}{\mathrm{dt}}} \\
& {\left[\phi_{3 \mathrm{~s}}\right]=\left[\mathrm{L}_{\mathrm{s}}\right]\left[\mathrm{I}_{3 \mathrm{~s}}\right]+\left[\mathrm{M}_{\mathrm{sr}}\right]\left[\mathrm{I}_{\mathrm{r}}\right]} \\
& {\left[\phi_{\mathrm{r}}\right]=\left[\mathrm{L}_{\mathrm{r}}\right]\left[\mathrm{I}_{\mathrm{r}}\right]+\left[\mathrm{M}_{\mathrm{rs}}\right]\left[\mathrm{I}_{\mathrm{s}}\right]}
\end{aligned}
$$

where $[\mathrm{V}]$ is the voltage vector, [I] is the current vector, $\left[\mathrm{R}_{\mathrm{S}}\right]_{3 \times 3}$ and $\left[\mathrm{R}_{\mathrm{r}}\right]_{N r \times N r}$ are the stator and the rotor resistances matrixes respectively. Whereas $\left[\mathrm{L}_{\mathrm{s}}\right]_{3 \times 3}$ is the stator winding inductance matrix, $\left[\mathrm{L}_{\mathrm{r}}\right]_{N r \times N r}$ is the rotor inductance matrix, $\left[\mathrm{M}_{\mathrm{sr}}\right]_{3 \times N r}$ is the mutual inductance matrix between stator and rotor. $\left[\phi_{\mathrm{s}}\right],\left[\phi_{\mathrm{r}}\right]$ are the stator and rotor flux vectors. The modeling details are presented in [22].

In a polyphase machine the electromagnetic torque equation is presented as:

$$
\mathrm{C}_{\mathrm{em}}=\sqrt{\frac{3}{2}} \mathrm{p} \mathrm{L}_{\mathrm{sr}}\left(\mathrm{I}_{\mathrm{qs}} \sum_{\mathrm{k}=0}^{\mathrm{Nr}-1} \mathrm{I}_{\mathrm{rk}} \cos (\mathrm{Ka})-\mathrm{I}_{\mathrm{ds}} \sum_{\mathrm{k}=0}^{\mathrm{Nr}-1} \mathrm{I}_{\mathrm{rk}} \sin (\mathrm{Ka})\right)
$$

with:

$$
\mathrm{L}_{\mathrm{sr}}=\frac{4 \mu_{0} \mathrm{~N}_{\mathrm{S}} \mathrm{RL}}{\mathrm{e} \pi \mathrm{p}^{2}} \sin (\mathrm{a} / 2), \mathrm{a}=\frac{2 \pi}{\mathrm{N}_{\mathrm{r}}} \mathrm{p} \text { and } \mathrm{K}=0, \ldots, \mathrm{Nr}
$$

$\mathrm{R}$, L, and e present the machine geometrical parameters, the air gap mean radius, the stack length, and the ring thickness respectively.

Furthermore, the rotor mechanical equations can be written as follows: 


$$
\left\{\begin{array}{c}
J \frac{d \omega}{d t}=C_{e m}-C_{r}-f_{v} \omega \\
\omega=\frac{d \theta}{d t}
\end{array}\right.
$$

where $C_{e m}$ is the electromagnetic torque, $C_{r}$ is the load torque, $\omega$ is the mechanical speed and $f_{v}$ is the friction coefficient.

\section{AUXILIARY WINDING VOLTAGE}

The technique is built considering an auxiliary winding inserted in the stator part as a small coil. Figure 1 shows the coil position that forms an angle $\theta_{0}$ with the A stator phase and has no conductive contact with other phases but is mutually coupled with all the other circuits in both the stator and rotor sides. This approach was applied previously to a wound rotor induction motor [23]-[25]. The voltage of the auxiliary winding is the main key of this method.

From solving the equation system above formed by (3) to (6) using Runge-Kutta numerical method, we obtain the main current vector which leads to the auxiliary winding flux:

$$
\varphi_{\text {aux }}=a \mathrm{I}_{\mathrm{sa}}+b \quad \mathrm{I}_{\mathrm{sb}}+c \mathrm{I}_{\mathrm{sc}}+\sum_{i=1}^{\mathrm{Nr}} d_{j} \mathrm{I}_{\mathrm{r} i}
$$

The coefficients $a, b, c$ related to the stator part are in function of the phase shifting $\theta_{0}$ and $d_{j}$ related to rotor part depend on time.

$$
\begin{array}{ll}
a=\mathrm{M}_{\text {saux }} \cos \left(\theta_{0}\right) & b=\mathrm{M}_{\text {saux }} \cos \left(\frac{2 \pi}{3}-\theta_{0}\right) \\
c=\mathrm{M}_{\text {saux }} \cos \left(\frac{4 \pi}{3}-\theta_{0}\right) & d_{j}=\mathrm{M}_{\text {raux }} \cos \left(\theta+\frac{j \pi}{3}\right), j=0,2,4 \ldots .
\end{array}
$$

$\mathrm{M}_{\text {saux }}$ is the mutuel inductance between the stator and the auxiliary winding

$\mathrm{M}_{\text {raux }}$ is the mutuel inductance between the rotor and the auxiliary winding

The auxiliary winding voltage expression as a function of its flux is:

$$
\mathrm{V}_{\mathrm{aux}}=\frac{\mathrm{d} \varphi_{\mathrm{aux}}}{\mathrm{dt}}
$$

The signal chosen for the FFT analysis is the auxiliary winding voltage, for that purpose, we should consider two other fictive coils forming together with the inserted coil a three-phase system.

$$
\begin{aligned}
& \mathrm{V}_{\text {auxa }}=\frac{\mathrm{d} \varphi_{\mathrm{auxa}}}{\mathrm{dt}}, \quad \mathrm{V}_{\mathrm{auxb}}=\frac{\mathrm{d} \varphi_{\mathrm{auxb}}}{\mathrm{dt}}, \quad \mathrm{V}_{\mathrm{auxc}}=\frac{\mathrm{d} \varphi_{\mathrm{auxc}}}{\mathrm{dt}} \\
& \varphi_{\text {auxa }}=\varphi_{\mathrm{sa}}+\varphi_{\mathrm{sb}}+\varphi_{\mathrm{sc}}+\sum_{i=1}^{\mathrm{Nr}} \varphi_{\mathrm{ri}}
\end{aligned}
$$

The simulation result doesn't change with applying different angle values, it does not depend on time therefore, we choose the $\theta 0=0$ for the next study. Thus, the flux expression is represented as:

$$
\varphi_{\text {auxa }}=M_{\text {saux }} I_{\text {sa }}-\frac{M_{\text {saux }}}{2} I_{s b}-\frac{M_{\text {saux }}}{2} I_{s c}+\sum_{i=1}^{N r} M_{\text {raux }} \cos \left(\theta+\frac{j \pi}{3}\right) I_{r i}, \quad j=0,2,4 \ldots
$$

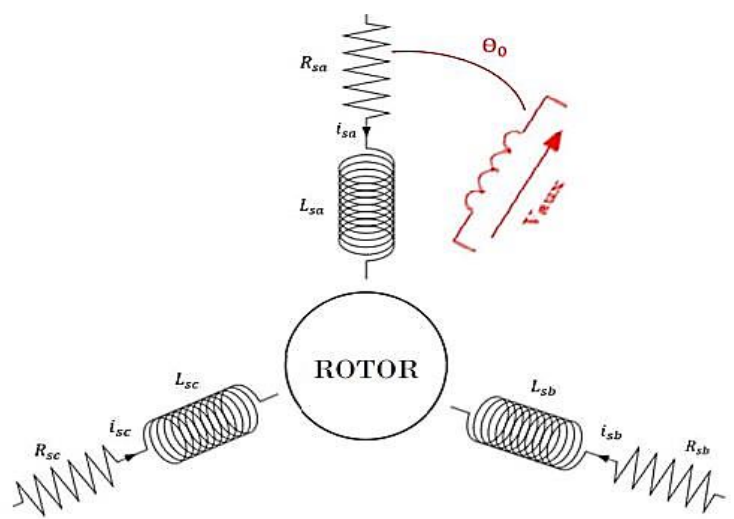

Figure 1. Auxiliary winding emplacement inside the squirrel cage induction motor 


\section{SIMULATION RESULT AND DISCUSSIONS}

The performance of the fault detection method proposed in this paper, is tested by simulations at different broken bars and end rings conditions under variable load. These simulations are carried out by Matlab for a 450W squirrel cage induction motor using the Hanning window. The machine parameters are given in Table 1.

Six different motor cases were simulated with increasing load level from $0.5-3 \mathrm{Nm}$. First, the case of a healthy motor is presented. Then the rotor bars breakage occurs gradually as follows: one broken bar case, two adjacent broken bars case, two separated broken bars case, one end ring case and two adjacent broken bars with end ring case.

The frequency domain shows the monitored signal present at varying frequencies. Therefore, the FFT applied to the auxiliary winding voltage with the sampling period of $T e=0.0056 \mathrm{~s}$ and the number of samples $\mathrm{N}=1000$, that illustrates the frequency spectrum of this signal for detectecting whether a rotor is faulty. The healthy motor cases are plotted for better comparison with rotor broken bars failure and different torques. From the simulation result, it appears clearly that the amplitude rises proportionally with increasing load whichever the faults are. At the beginning of the simulation, the motor is healthy and unloaded. Figure 2(a) shows the peak of the first harmonic at $100 \mathrm{~Hz}$ and the auxiliary voltage amplitude stays at $68 \mathrm{~V}$. Whereas at $\mathrm{Cr}=3 \mathrm{Nm}$ the amplitude has increased to $74 \mathrm{~V}$ and some sideband harmonics appear in different frequencies, but the most significant is the one at $92 \mathrm{~Hz}$ caused by load as shown in Figure 2(b). This means that the load is also considered as a disturbance and that the signal can inform us about the presence of an overload. All the figures of the auxiliary winding voltage presented below are under load of $\mathrm{Cr}=3 \mathrm{Nm}$.

The healthy state is considered as the reference state. The results obtained in this case describe the characteristics of the signal used which is the voltage of the auxiliary winding. For the rotor broken bars and end rings faults it can be seen in those graphs that the peaks developed has different frequencies. Those peaks amplitudes of the auxiliary winding voltage increase according to the failures gravity and the number of the bars broked. Furthermore, increasing load affect the shape and the size of the side lobe peaks.

Figure 3 shows the spectrum of the auxiliary voltage with one broken bar fault. The high frequency oscillation is at $79 \mathrm{~Hz}$. For $\mathrm{Cr}=0.5 \mathrm{Nm}$, the main peak has an amplitude equals to $52 \mathrm{~V}$. This amplitude rises to $85 \mathrm{~V}$ at $\mathrm{Cr}=1.875 \mathrm{Nm}$ and to $118 \mathrm{~V}$ at $\mathrm{Cr}=3 \mathrm{Nm}$. Moreover, other diffrent peaks appear between $70 \mathrm{~Hz}$ and $90 \mathrm{~Hz}$ margins. Their size and shape changes depending on the load level. The most viewable peak is the one at $80 \mathrm{~Hz}$. It corresponds to an amplitude of $22 \mathrm{~V}$ in the first level. The largest peak at $85 \mathrm{~Hz}$ corresponds to an amplitude of $27 \mathrm{~V}$ in the second level. For the third load level two significant peaks appear at $87 \mathrm{~Hz}$ and at $90 \mathrm{~Hz}$ having an amplitude of $38 \mathrm{~V}$ and $85 \mathrm{~V}$ respectively.
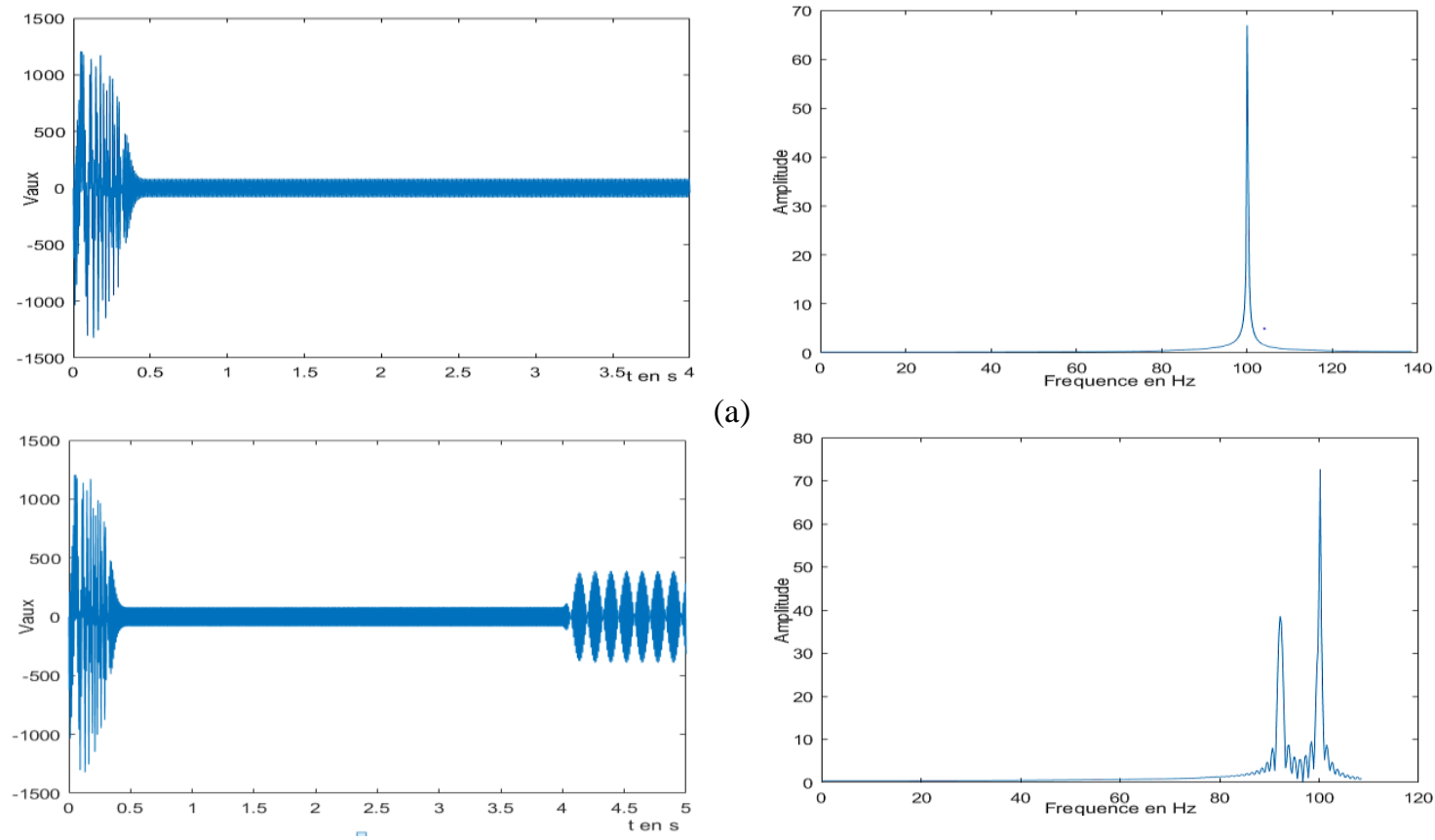

(a)

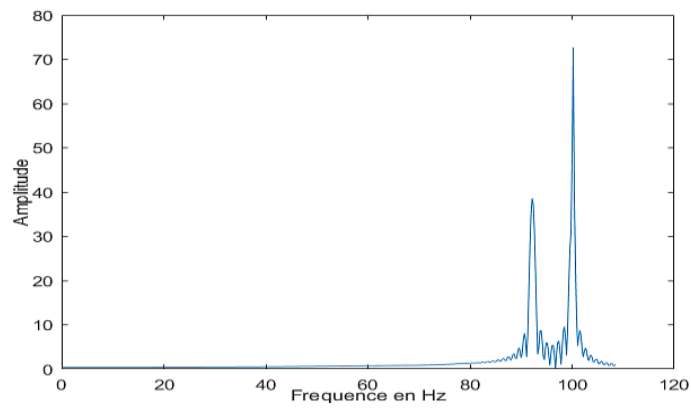

(b)

Figure 2. FFT of auxiliary winding voltage for a healthy motor; (a) In case of $\mathrm{Cr}=0 \mathrm{Nm}$,

(b) In case of $\mathrm{Cr}=3 \mathrm{Nm}$ 
Table 1. Squirrel cage induction motor parameters

\begin{tabular}{clc}
\hline Symbol & \multicolumn{1}{c}{ quantity } & Value \\
\hline $\mathrm{V}$ & Power supply voltage & $220 / 380 \mathrm{~V}$ \\
$\mathrm{f}$ & Frequency & $50 \mathrm{~Hz}$ \\
$\mathrm{p}$ & Number of pole paires & 1 \\
$\mathrm{~N}_{\mathrm{r}}$ & Number of rotor bars & 27 \\
$\mathrm{~N}_{\mathrm{s}}$ & Number of stator slots & 193 \\
$\mathrm{E}$ & Ring thickness & $0.38 \mathrm{~mm}$ \\
$\mathrm{R}$ & Air gap mean radius & 37.5 \\
$\mathrm{~L}$ & Stack length & $60 \mathrm{~mm}$ \\
$\mathrm{R}_{\mathrm{s}}$ & Resistanthe stator winding & $4.1 \Omega$ \\
$\mathrm{R}_{\mathrm{b}}$ & Resistance of a rotor bar & $74 \mu \Omega$ \\
$\mathrm{R}_{\mathrm{e}}$ & Resistance of the rotor end ring & $74 \mu \Omega$ \\
$\mathrm{L}_{\mathrm{b}}$ & Leakage inductance of rotor bars & $0.33 \mu \mathrm{H}$ \\
$\mathrm{L}_{\mathrm{e}}$ & Leakage inductance of rotor end rings & $0.33 \mu \mathrm{H}$ \\
$\mathrm{J}$ & Moment of inertia & $10^{-3} \mathrm{Nms} \mathrm{s}^{2}$ \\
\hline
\end{tabular}
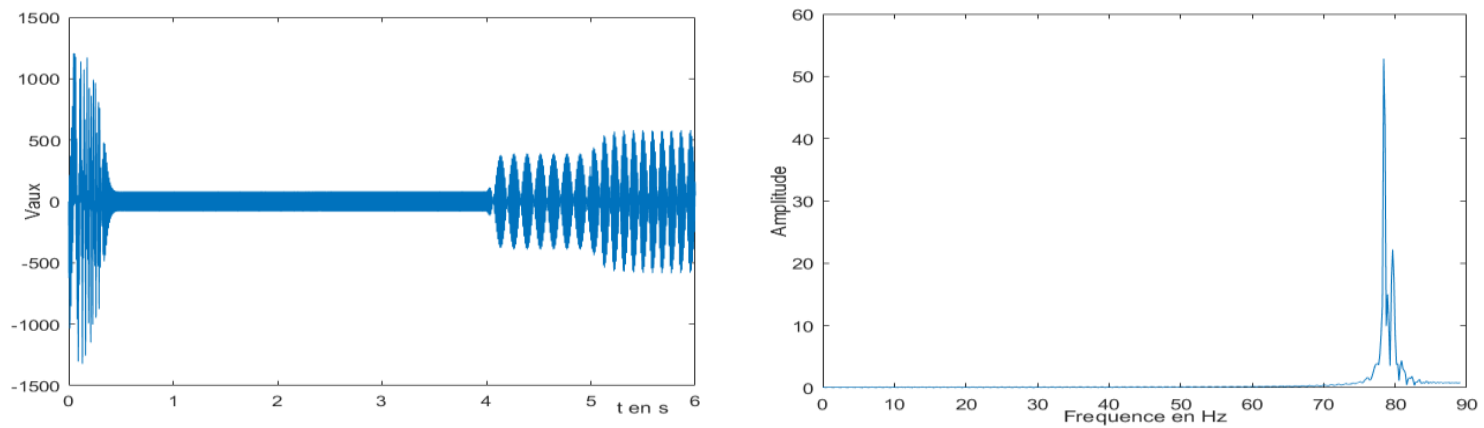

(a)

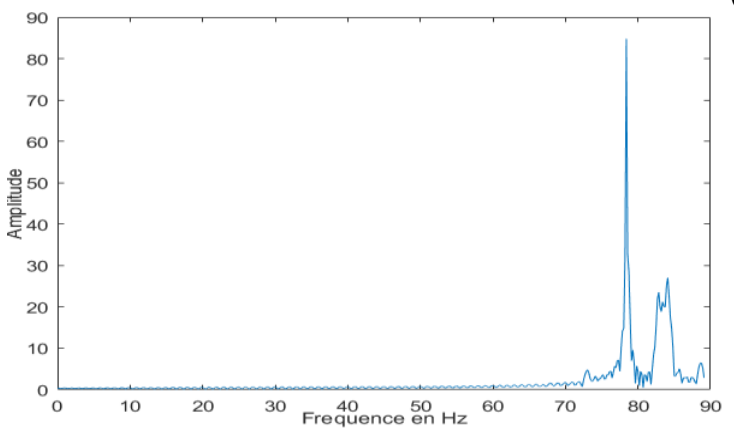

(b)



(c)

Figure 3. Spectrum of auxiliary winding voltage for one broken bar motor; (a) In case of $\mathrm{Cr}=0.5 \mathrm{Nm}$, (b) In case of $\mathrm{Cr}=1.875 \mathrm{Nm}$, (c) In case of $\mathrm{Cr}=3 \mathrm{Nm}$

In the case of two adjacent broken bars there are different peaks that vary in size, amplitude and shape in $40 \mathrm{~Hz}$ and $75 \mathrm{~Hz}$ margins. The main peak appears at $53 \mathrm{~Hz}$ when $\mathrm{Cr}=0.5 \mathrm{Nm}$ in Figure 4(a). Its amplitude is $60 \mathrm{~V}$. Another significant peak is detected at $54 \mathrm{~Hz}$ with an amplitude of $22 \mathrm{~V}$. The increasing load to $\mathrm{Cr}=1.875 \mathrm{Nm}$ leads the amplitude of the main peak rise to $109 \mathrm{~V}$ and the appearance of a larger peak shown at $57 \mathrm{~Hz}$. Its amplitude is $30 \mathrm{~V}$ as shown in Figure 4(b). The amplitude continuously rises according to the load. In Figure $4(\mathrm{c})$, for $\mathrm{Cr}=3 \mathrm{Nm}$, the hight frequency reaches $150 \mathrm{~V}$. More other peaks appear at $59 \mathrm{~Hz}, 64 \mathrm{~Hz}$ and $66 \mathrm{~Hz}$. Their amplitude is $25 \mathrm{~V}, 49 \mathrm{~V}$ and $47 \mathrm{~V}$ respectively.

The two separated broken bar case in Figure 5 shows a frequency band from 40 to $75 \mathrm{~Hz}$. For $\mathrm{Cr}=0.5 \mathrm{~Hz}$ two peaks appear: the main harmonic is at $52 \mathrm{~Hz}$ with an amplitude of $60 \mathrm{~V}$ and the other one at $54 \mathrm{~Hz}$ corresponding to an amplitude of $15 \mathrm{~V}$ as shown in Figure 5(a). These changes depend on the increasing load. With $\mathrm{Cr}=1.875 \mathrm{Nm}$ more other peaks appear as shown in Figure 5(b), the significant ones are at $55 \mathrm{~Hz}, 58 \mathrm{~Hz}$ and $60 \mathrm{~Hz}$ corresponding respectively to 20,25 and $17 \mathrm{~V}$. The main frequency amplitude is $95 \mathrm{~V}$. At full a load $\mathrm{Cr}=3 \mathrm{Nm}$, multiple frequencies appear. The viewable peaks are at $58,63 \mathrm{~Hz}$ and a larger peak arises at $72 \mathrm{~Hz}$. Their amplitude changes to 25, 42 and $20 \mathrm{~V}$ respectively in Figure 5(c). The highest frequency reaches $130 \mathrm{~Hz}$.

The broken end ring spectrum presents two significant peaks in different load level. But the amplitude and the frequency change as shown in Figure 6. The main harmonic is at $78 \mathrm{~Hz}$; its amplitude rises 
with the load level of $55 \mathrm{~V}$ to $100 \mathrm{~Hz}$. In Figure 6(a) for $\mathrm{Cr}=0.5 \mathrm{Nm}$ a second peak appears at $80 \mathrm{~Hz}$ corresponding to an amplitude of $20 \mathrm{~V}$. When the load rises to $\mathrm{Cr}=1.875 \mathrm{Nm}$ in Figure 6(b), the peak appears at $84 \mathrm{~Hz}$ and the amplitude rises to $40 \mathrm{~Hz}$. The second peak illustrated in Figure 6(c) appears at $87 \mathrm{~Hz}$ and reaches an amplitude of $65 \mathrm{~V}$ for a $\mathrm{Cr}=3 \mathrm{Nm}$.
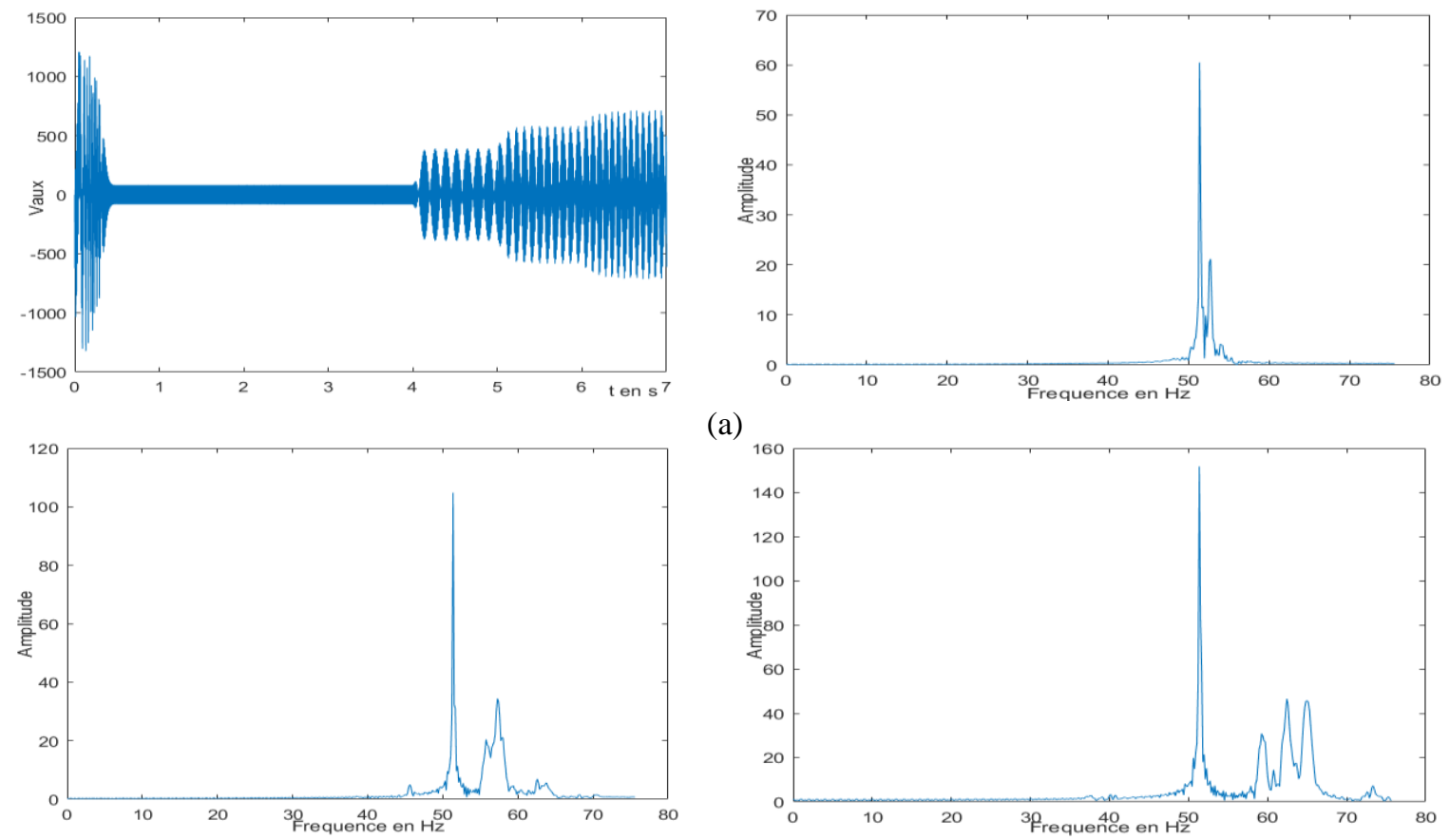

(a)

(b)

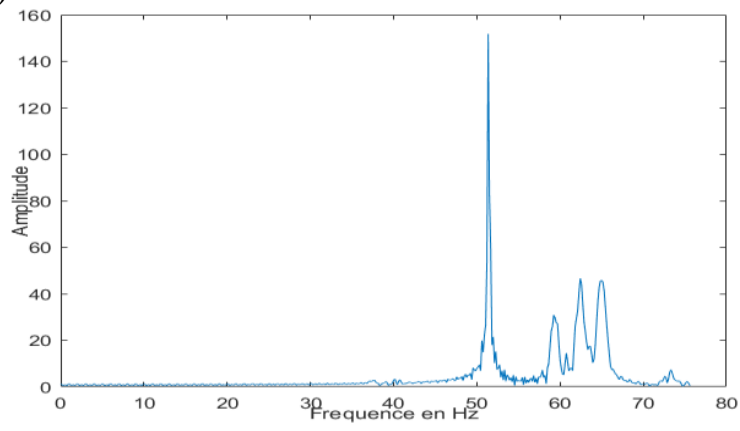

(c)

Figure 4. FFT spectrum of auxiliary winding voltage for two adjacent broken bars; (a) In case of $\mathrm{Cr}=0.5 \mathrm{Nm}$, (b) In case of $\mathrm{Cr}=1.875 \mathrm{Nm}$, (c) In case of $\mathrm{Cr}=3 \mathrm{Nm}$
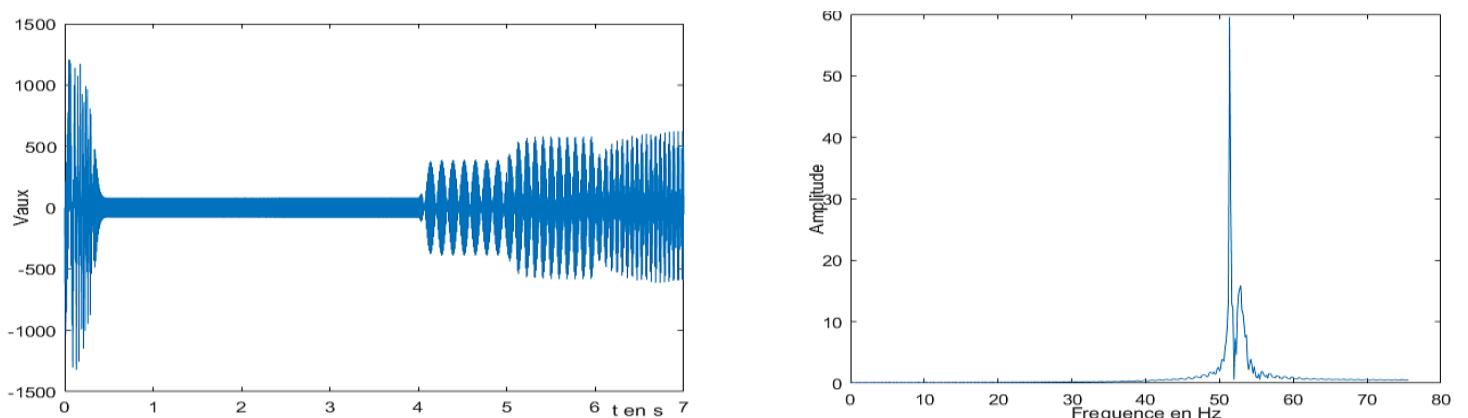

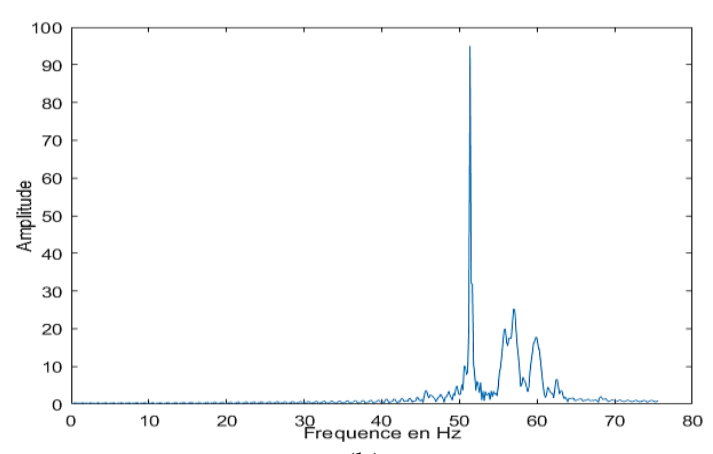

(b) (a)

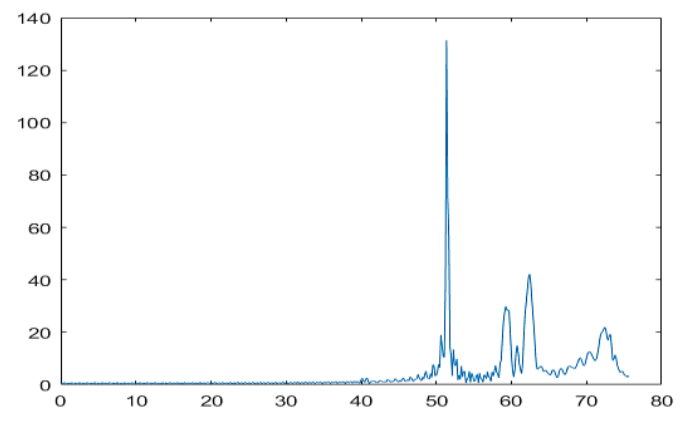

(c)

Figure 5. FFT spectrum of auxiliary winding voltage for two separated broken bars: (a) In case of $\mathrm{Cr}=0.5$ $\mathrm{Nm}$, (b) In case of $\mathrm{Cr}=1.875 \mathrm{Nm}$, (c) In case of $\mathrm{Cr}=3 \mathrm{Nm}$ 

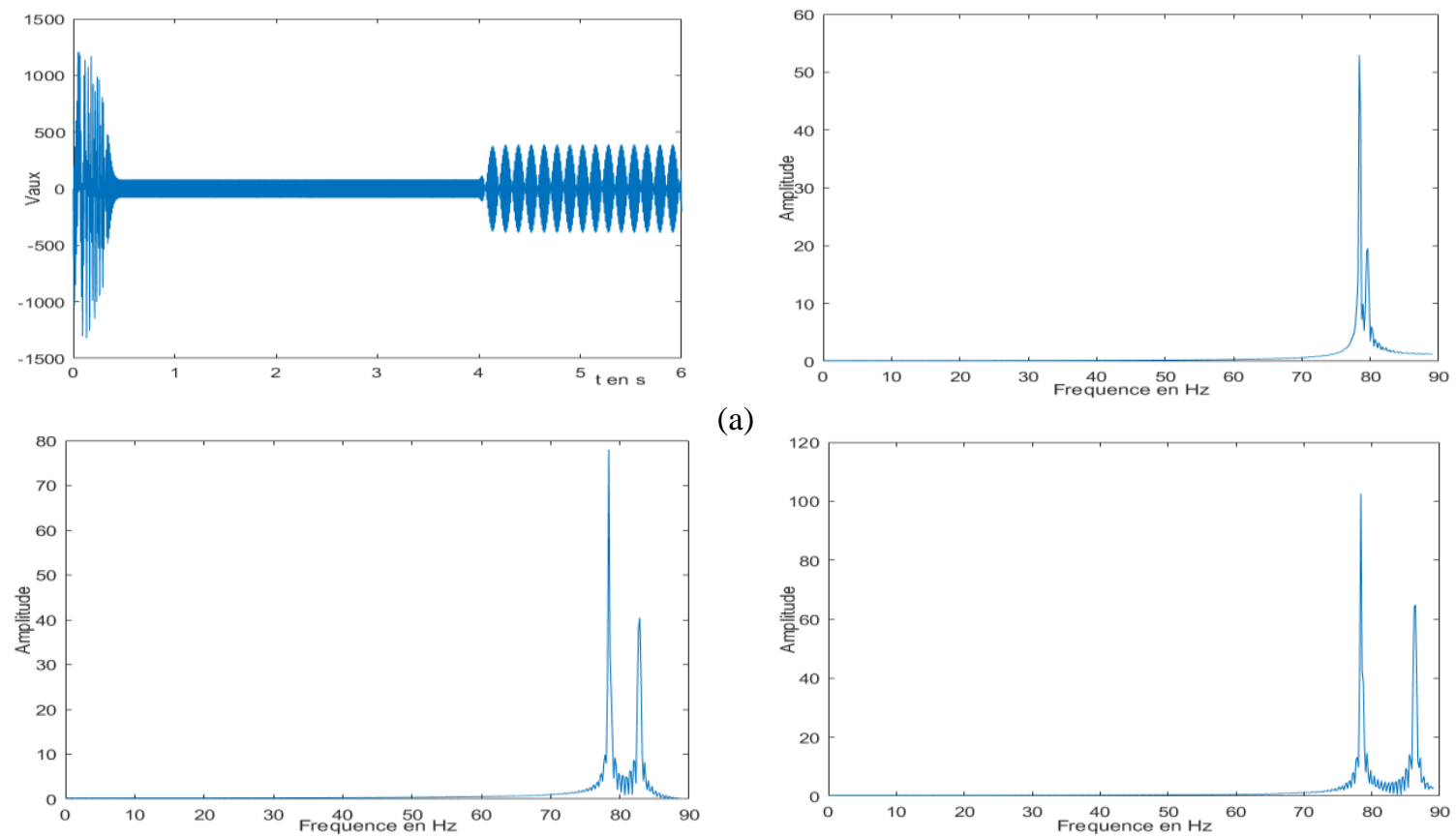

(a)

(b)

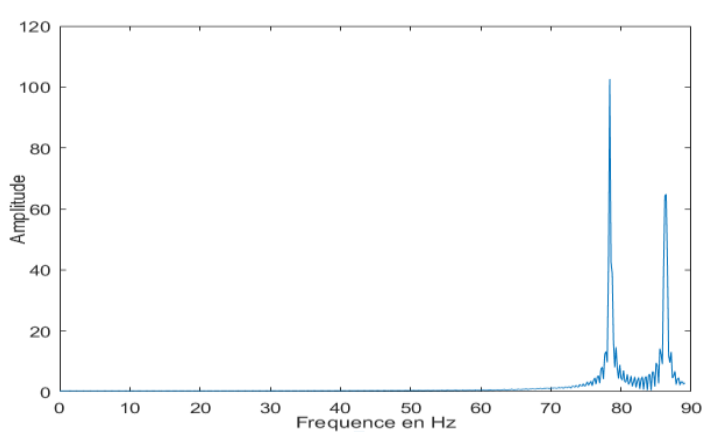

(c)

Figure 6. FFT spectrum of auxiliary winding voltage for a broken end ring, (a) In case of $\mathrm{Cr}=0.5 \mathrm{Nm}$, (b) In case of $\mathrm{Cr}=1.875 \mathrm{Nm}$, (c) In case of $\mathrm{Cr}=3 \mathrm{Nm}$

In the case of two broken bars with a broken end ring, the graphs in figure 7 show that the peak frequencies range is from $19 \mathrm{~Hz}$ to $60 \mathrm{~Hz}$ which is the largest frequency band. Also, the main frequency occurs at $32 \mathrm{~Hz}$ and its amplitude rises from $65 \mathrm{~V}$ to $170 \mathrm{~V}$. In Figure 7(a) the second peak appears at $33 \mathrm{~Hz}$ corresponding to an amplitude of $25 \mathrm{~V}$. Substantial peaks appear in Figure 7(b) between $35 \mathrm{~Hz}$ and $39 \mathrm{~Hz}$ corresponding to an amplitude of almost $38 \mathrm{~V}$ for a $\mathrm{Cr}=1.875 \mathrm{Nm}$. For a full load $\mathrm{Cr}=3 \mathrm{Nm}$, the peaks occur between $39 \mathrm{~Hz}$ and $48 \mathrm{~Hz}$. Their amplitude reaches almost $45 \mathrm{~V}$ as it is shown in Figure 7(c).


(a)

(b)



(c)

Figure 7. FFT spectrum of auxiliary winding voltage for two adjacent broken bars with end ring; (a) In case of $\mathrm{Cr}=0.5 \mathrm{Nm}$, (b) In case of $\mathrm{Cr}=1.875 \mathrm{Nm}$, (c) In case of $\mathrm{Cr}=3 \mathrm{Nm}$ 


\section{CONCLUSION}

In this paper, the fast Fourier transform spectrum is presented to detect the broken bars and end rings fault in the squirrel cage induction machine using the auxiliary winding voltage as the monitored signal. The simulation results showed a very clear differences between the six fault cases. The frequency band related to each kind of failure and the amplitude of the peaks depends on the fault degree and the load level. The shift of this frequency band presents the faults characteristics, the more the motor is loaded, the more the number of the peaks arises and their amplitude increases. Moreover, the fault severity and the number of the broken bars influence the spectrum. The FFT of the auxiliary winding voltage makes the occurrence of the noticeable fault. It has a satisfactory result for on-line monitoring by detecting failure in an early stage and avoid the drive breakdown. For more accuracy, another diagnostic technique will be used in the future work. It is based on the Wavelet transform to detect temporary broken bars and end rings faults in squirrel cage induction motor.

\section{REFERENCES}

[1] T. Aroui, Y. Koubaa, and A. Toumi, "Modeling and Diagnostics of Inductions Machines Under Rotor Failure," ICGST-ACSE Journal, vol. 7, no. 2, pp. 9-18, Nov 2007.

[2] J. Y. Khadouj and E. M. Lamiaà, "Electromechanical Conversion Chain Fault Diagnostic-State of Art," Conférence Internationale en Automatique \& Traitement de Signal (ATS-2018), vol. 36, pp. 1-5, 2018.

[3] C. Concari, G. Franceschini, C. Tassoni, and S. Member, "Differential Diagnosis Based on Multivariable Monitoring to Assess Induction Machine Rotor Conditions," IEEE Trans. Ind. Electron, vol. 55, no. 12, pp. 4156-4166, 2008, doi: 10.1109/TIE.2008.2003212.

[4] Y. Jun Yoo, "Fault Detection of Induction Motor Using Fast Fourier Transform with Feature Selection via Principal Component Analysis," International Journal of Precision Engineering and Manufacturing, vol. 20, no. 9, pp. 1543-1552, 2019, doi: 10.1007/s12541-019-00176-z.

[5] O. Duque-Perez, L. A. Garcia-Escudero, D. Morinigo-Sotelo, P. E. Gardel, and M. Perez-Alonso, "Analysis of fault signatures for the diagnosis of induction motors fed by voltage source inverters using ANOVA and additive models," Electr. Power Syst. Res, vol. 121, pp. 1-13, 2015, doi: 10.1016/j.epsr.2014.11.021.

[6] A. Bellini, F. Filippetti, C. Tassoni, and G. A. Capolino, "Advances in diagnostic techniques for induction machines," IEEE Trans. Ind. Electron., vol. 55, no. 12, pp. 4109-4126, 2008, doi: 10.1109/TIE.2008.2007527.

[7] A. Naha, A. K. Samanta, A. Routray, and A. K. Deb, "A method for detecting half-broken rotor bar in lightly loaded induction motors using current," IEEE Trans. Instrum. Meas, vol. 65, no. 7, pp. 1614-1625, 2016, doi: 10.1109/TIM.2016.2540941.

[8] H. Çaliş and A. Çakir, "Rotor bar fault diagnosis in three phase induction motors by monitoring fluctuations of motor current zero crossing instants," Electr. Power Syst. Res, vol. 77, no. 5-6, pp. 385-392, 2007, doi: 10.1016/j.epsr.2006.03.017.

[9] P. K. Kankar, S. C. Sharma, and S. P. Harsha, "Rolling element bearing fault diagnosis using autocorrelation and continuous wavelet transform," JVC/Journal Vib. Control, vol. 17, no. 14, pp. 2081-2094, 2011, doi: 10.1177/1077546310395970.

[10] W. Dehina, M. Boumehraz, and F. Kratz, "Diagnosis of Rotor and Stator Faults by Fast Fourier Transform and Discrete Wavelet in Induction Machine," 2018 Int. Conf. Electr. Sci. Technol. Maghreb, pp. 1-6, 2018, doi: 10.1109/CISTEM.2018.8613311.

[11] J. Burriel-valencia, R. Puche-panadero, J. Martinez-roman, A. Sapena-bano, and M. Pineda-sanchez, "Short-Frequency Fourier Transform for Fault Diagnosis of Induction Machines Working in Transient Regime," IEEE Trans. Instrum. Meas, vol. 66, no. 3, pp. 432-440, 2017, doi: 10.1109/TIM.2016.2647458.

[12] M. Pineda-sanchez and J. a Antonino-daviu, "Diagnosis of Induction Motor Faults in the Fractional Fourier Domain Manuel," IEEE Trans. Instrum. Mea, vol. 59, no. 8, pp. 2065-2075, 2010, doi:10.1109/TIM.2009.2031835.

[13] A. Menacer, M. d N. T-Said, A. Benakcha, and S. Drid, "Stator Current Analysis of Incipient Fault into Asynchronous Motor Rotor Bars using Fourier Fast Transform,” J. Electr. Eng, vol. 55, no. 5, pp. 122-130, 2014.

[14] P. Karvelis, G. Georgoulas, I. P. Tsoumas, J. A. Antonino-Daviu, V. Climente-Alarcón, and C. D. Stylios, "A Symbolic Representation Approach for the Diagnosis of Broken Rotor Bars in Induction Motors," IEEE Trans. Ind. Informatics, vol. 11, no. 5, pp. 1028-1037, 2015, doi: 10.1109/TII.2015.2463680.

[15] W. T. Thomson, and Ian Culbert."Current Signature Analysis for Condition Monitoring of Cage Induction Motors: Industrial Application and Case Histories," The Institute of Electrical and Electronics Engineers, First Edition, pp. 79-118, 2017.

[16] M. A. AL-Yoonus and O. S. Al-deen Alyozbaky "Detection of internal and external faults of single-phase induction motor using current signature." International Journal of Electrical and Computer Engineering, vol. 11, no. 4, pp. 2830-2841, 2021, doi: 10.11591/ijece.v11i4.pp2830-2841.

[17] R. R. Rivera, S. Member, and H. A. Larrondo, "A Simple Adjustable Window Algorithm to Improve FFT Measurements," IEEE Trans. Instrum. Meas, vol. 51, no. 1, pp. 31-36, 2002, doi: 10.1109/19.989893

[18] Salih Mohammed Salih "Fourier Transform-Signal Processing," IntechOpen, pp. 354, Apr. 2012, doi: 10.5772/813. Available from: https://www.intechopen.com/books/fourier-transform-signal-processing

[19] K. Fu and Y. Feng, "Combining the Hanning windowed interpolated FFT in both directions," Computer Physics Communications, vol. 178, no. 12, pp. 924-928, 2008, doi: 10.1016/j.cpc. 2008.02. 008. 
[20] A. Ibrahim and M. Marei, "Modeling of induction motor based on winding function theory to study motor under stator/rotor internal faults," IEEE proceedings, MEPCON, no. 1, pp. 494-500, 2010

[21] P. Shi, Z. Chen, Y. Vagapov, and Z. Zouaoui, "A new diagnosis of broken rotor bar fault extent in three phase squirrel cage induction motor," Mech. Syst. Signal Process., vol. 42, no. 1-2, pp. 388-403, 2014, doi: 10.1016/j.ymssp.2013.09.002.

[22] Y. Liu, L. Guo, Q. Wang, G. An, M. Guo, and H. Lian, "Application to induction motor faults diagnosis of the amplitude recovery method combined with FFT,” Mech. Syst. Signal Process., vol. 24, no. 8, pp. 2961-2971, 2010, doi: 10.1016/j.ymssp.2010.03.008

[23] Y. K. Jelbaoui, E. M. Lamiaà, and A. Saad, "Fault diagnosis of a squirrel cage induction motor fed by an inverter using lissajous curve of an auxiliary winding voltage," Indones. J. Electr. Eng. Comput. Sci., vol. 21, no. 3, pp. 1299-1308, 2021, doi: 10.11591/ijeecs.v21.i3.pp1299-1308.

[24] L. El Menzhi and A. Saad, "Lissajous curve of an auxiliary winding voltage park components for diagnosing multiple open switches faults in three phase inverter," Appl. Mech. Mater, vol. 672-674, pp. 1224-1233, oct. 2014, doi: 10.4028/www.scientific.net/AMM.672-674.1224.

[25] L. El Menzhi and A. Saad, "Induction motor fault diagnosis using voltage spectrum of auxiliary winding and lissajous curve of its park components," Adv. Mater. Res, vol. 805-806, pp. 963-979, 2013, doi: 10.4028/www.scientific.net/AMR.805-806.963.

\section{BIOGRAPHIES OF AUTHORS}
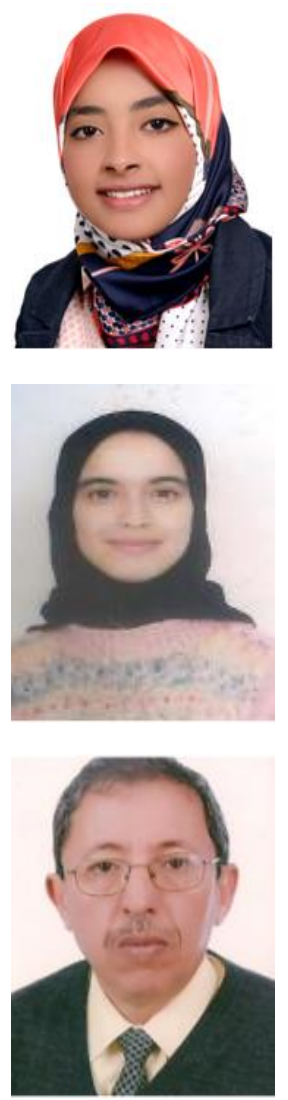

Yakout Khadouj Jelbaoui was born in Morocco on jully 1992. In 2015, she received the Engineer degree in Mechatronics from the National School of Applied Sciences, Abdelmalek Essaadi University of Morocco in Tetouan. She is PhD student in Electricotechnical engineering at National School of Applied Sciences in Tangier since novembre 2016. She is interested in electrical machines and electrical devices modeling, control and on-line diagnosis defects

Lamiaa EI Menzhi is a professor in AbdelamalekEssaadi University in Morocco since 2010. On 2002, She got her High Deepened Studies Diploma in electrical engineering from the High National School of Electricity and Mechanics ENSEM in Hassan 2 University in Casablanca. From 2002 until 2004, she was a research student in one of the universities in japan. On 2009, she obtained her Doctor degree, then her Habilitation as a professor researcher on 2016 from Hassan 2 University in Casablanca (ESEM). She is interested in electrical machines control and on-line diagnosis either used as a motor or a generator in wind turbines. Lamiaa El Menzhi is a member and advisor of the Moroccan Center of Polytechnical Research and Innovation since 2015.

\begin{abstract}
Abdallah Saad was born in Morocco in September 1956. He received the Engineer and Doctor of Engineering degrees from National Polytechnic Institute of Grenoble France respectively in 1980 and 1982. From 1982 to 1986, he was Researcher at French National Center for Scientific Research (CNRS) - Electrostatics and Dielectric Materials Laboratory Grenoble. After receiving the Doctor of Physical Sciences degree in 1986, he joined Hassan 2 University of Morocco. Professor of electrical engineering, he has several scientific and educational responsibilities. His main fields of interest are High Voltage and Electrical Insulations, modeling and control, renewable energy integration.
\end{abstract}

